\title{
Crise, movimento popular, intervenção estrangeira e a presença da América Latina e do Brasil no Haiti ${ }^{1}$
}

Rosny Smarth ${ }^{2}$

\section{Crise e movimento popular no Haiti}

A queda de Duvalier em 1986 se deveu a uma grande mobilização popular que tomou força em novembro de 1985, pôs abaixo o governo de Baby Doc em 7 de fevereiro 1986 e, de certa forma, seguiu seu curso até os dias de hoje.

Tem se falado de um movimento espontâneo, gelatinoso, sem direção política. Um movimento antiestado, antipartido, um movimento com fortes demandas de justiça social e de igualdade.

Não vamos entrar em uma análise detalhada da origem desse movimento social. Basta dizer que é fruto de um trabalho amplo dos setores progressistas e patrióticos, os quais, apesar do fechamento dos espaços democráticos, na ditadura de Duvalier, têm aproveitado as poucas brechas abertas para fazer habilmente ativismo político. Nesse sentido, as igrejas, em particular a Igreja Católica, gozou de espaços para que, por meio de suas Pastorais e das ONGs, pudesse sensibilizar a população pouco a pouco e preparar seus fiéis para a mudança de regime. Muitas outras organizações, como a imprensa e grupos de profissionais que trabalhavam principalmente no mundo rural, fizeram também um trabalho inteligente de oposição à ditadura.

O movimento social que derrubou Duvalier pretendia mudar não somente o regime político, mas o próprio sistema de dominação vigente. Poderíamos dizer inclusive que pretendia acabar com o sistema capitalista e que teria intenções revolucionárias. Mudar o Estado era seu lema, ou seja, queria terminar com o Estado

1 Texto produzido por ocasião do Simpósio Internacional Caminhos de Diálogo para a Construção de uma Diplomacia Responsável- a Presença do Brasil no Haiti, realizado no UNICEUB de 27 a 29 de março de 2007. Traduzido do espanhol por Renata de Melo Rosa.

2 Ex-primeiro ministro haitiano. Líder do partido haitiano OPL - Organization de Peuple en lutte. 
oligárquico, burgês, capitalista etc. Mas como fazê-lo e por que substituí-lo, era a questão.

Dentro do movimento havia pequenos grupos marxistas, com claras tendências socialistas, mas em evidente posição minoritária. O grosso do movimento não sabia aonde ia, não tinha uma ideologia clara, salvo que reclamava com força a justiça social e a igualdade. Em grande parte, era de tendência antiestruturalista pois reivindicava a horizontalidade absoluta. Nesse sentido, não suportava a possibilidade de uma vanguarda revolucionária nem de um partido orgânico para fazer a "revolução".

Ademais, a conjuntura internacional e regional não era favorável a nenhum tipo de revolução. Por um lado, o mundo socialista havia se desintegrado no início dos anos 80 e, por outro lado, os regimes ditatoriais militares atravessavam sérias dificuldades para se manterem no poder, sendo fortemente sacudidos pelas reivindicações que iniciavam o que iria se chamar de "transição democrática", principalmente no Cone Sul.

É necessário dizer que os partidos políticos de tendência revolucionária na história do Haiti não haviam conseguido realizar uma verdadeira inserção nas massas. O mais sólido foi o PUCH (Partido Unificado dos Comunistas Haitianos) que, nos anos 70, chegou a fazer algumas ações espetaculares em Porto Príncipe e sobretudo chegou a implantar uma pequena comunidade perto de Porto Príncipe - Cazale. O regime dos Duvalier operou ali um verdadeiro massacre para acabar com qualquer semente revolucionária.

O Haiti não poderia escapar da onda de “transição democrática”. Depois da queda do sistema socialista, a globalização se manifestou não somente no plano econômico, mas também a democracia representativa apareceu como o modelo, como o paradigma político que iria assegurar a modernidade dessa mundialização. Esse novo paradigma iria colocar abaixo os velhos sistemas ditatoriais e oligárquicos no continente. A doutrina de segurança nacional que havia sustentado os militares e as ditaduras civis para justificar os golpes de estado a se manterem no poder foi derrotada por si mesma e as eleições apareceram como a única forma admissível para ascender ao poder. 
De acordo com o que foi dito anteriormente, as condições estavam como dadas para um populismo de esquerda. Como se sabe, o populismo é uma forma de governo compatível com o sistema democrático. Assim, os populismos prosperam dentro do sistema democrático. É possível dizer que se trata de uma distorção, às vezes uma perversão dentro do sistema, sem que se rompa com ele. Mantém certos princípios do jogo democarático, por exemplo, a necessidade de legitimidade via eleições gerais.

Uma das características básicas do populismo é a forte interpelação popular que dá lugar ao que se tem chamado fusão líder-povo. Uma espécie de forte identificação emocional entre o líder e as clases subalternas, sobretudo as categorias marginalizadas dos grandes centros urbanos. A relação entre o líder e o povo tende a ser direta, sem estruturas de mediação, quer sejam partidos, parlamentos etc. Embora essas estruturam existam, o líder tende a passar por cima delas e realizar diretamente a fusão emocional com o povo. No entanto, não há democracia verdadeira sem mediações, sem estruturas suscetíveis de construção de um elo entre o poder e a população ; e de canalizar as demandas e reivindicações dos diversos setores. Essas estruturas são as que colocam limitações de poder ao líder, que filtram e processam as demandas e que podem realizar o que se chama de « check and balance » em um sistema demócratico.

Bem, diremos que, da queda de Duvalier às eleições que levaram Jean Bertrand Aristide ao poder, no final de 1990, o movimento popular deu uma demonstração de força sem igual para impedir o retorno às formas ditatoriais sob o comando das forças armadas. Foi um período extremamente instável com grandes mobilizações populares contra os quatro governos que, de fato, tentaram refundar o velho sistema autocrático.

No final das contas, o movimento popular ganhou a batalha, mediante a vitória inquestionável de seu líder Jean Bertrand Aristide, nas eleições gerais de dezembro de 1990. O governo de Arisitide duraria muito pouco: de fevereiro a setembro de 1991, ou seja, escassos sete meses.

No entanto, os métodos populistas de Aristide começaram a emergir fortemente. O governo não formou um corpo administrativo. Muito acima 
das estruturas estava o presidente que criticava seus ministros publicamente e chegava inclusive a se declarar em oposição a seu próprio poder. Havia poucas preocupações pela institucionalidade democrática. $O$ Executivo resistiu ao controle do Parlamento e o primeiro ministro respondeu às convocatórias do Parlamento, com manifestações de massa e com ameaças aos parlamentares. Cabe ressaltar que isso seria uma forte característica da forma de governar do presidente Aristide: a de tentar resolver os conflitos de poder fora dos canais institucionais e via mobilização das massas. Nesse marco, a oposição política e as forças sociais que não estavam de acordo com o governo nunca se sentiram em segurança. Em vez de acalmar o ambiente, Aristide se dedicou a esquentá-lo. Já as mudanças que fez nas Forças Armadas no mesmo dia de sua chegada ao poder eram preocupantes, sendo o general Abraham, o então Chefe das Forças Armadas, um homem conhecido por seu equilíbrio. Do General Cèdras ${ }^{3}$, sabia-se muito pouco, mas dizia-se que o homem passou a se mostrar partidário do novo chefe de Estado. Em síntese, com inimigos tão fortes como a burguesia, as forças armadas e os norte-americanos, Aristide deveria buscar novas alianças e acalmar o jogo em sua chegada ao poder. $\mathrm{O}$ apoio somente das classes populares e subalternas se mostraria bastante insuficiente. No fundo, as condições para um golpe de estado estavam bem presentes.

Como coloquei em outras ocasiões, à derrota militar do movimento popular e do governo de Aristide seguiu a sua derrota política. Foi a derrota política que facilitou o fracaso militar. No entanto, o movimento popular viveu a queda de Aristide como um fracasso militar. Nunca se disse que, nas circunstâncias de fragilidade da ascensão de Aristide, os problemas de aliança ou de criação de consenso teriam valores estratégicos. Pensou-se que pela combatividade e mobilização das massas seria possível parar qualquer tentativa de golpe (como foi com a tentativa do ex-homem forte do regime de Duvalier, Roger Lafontant de aplicar um golpe de Estado justo antes da chegada de Aristide ao poder). O movimento popular, com Aristide à frente, mostrou suas limitações para forjar governabilidade e estabilidade, condição sine qua non para a melhoria das condições sociais e econômicas da grande maioria excluída.

\footnotetext{
3 Autor do golpe de Estado a Aristide em setembro de 1991. Nota da tradutora.
} 
Bem, sabe-se que depois do golpe militar e do exílio do presidente, o movimento popular continuou tensionando e exigindo o retorno do líder, tornando o país ingovernável por parte dos militares e de seus partidários. O governo norte-americano se deu conta que a única saída possível para a governabilidade era o retorno do presidente eleito legitimamente. Passou então a trabalhar para forjar o consenso entre Aristide e os militares, mediante a assinatura do Acordo da Ilha dos Governadores, em Nova Iorque. As barbaridades dos militares, a onda de repressão e violação dos direitos individuais mais elementares haviam debilitado ao extremo o governo do general Cedras. Aristide assim o entendeu e, ao final de contas, não houve assinatura de Acordo. A única saída então era o retorno pela força de Aristide, o que implicava derrotar os militares. Daí a invasão de 20.000 soldados americanos em setembro de 1994. À derrota militar seguiu a derrota política. A única saída dos militares era buscar um acordo político com Aristide. Se não fizessem, sua queda era iminente. Uma vez mais, o movimento popular havia demonstrado sua força para resistir e cavar trincheiras para conseguir o retorno de Aristide. Sua debilidade parecia residir na fragilidade para dirigir e assegurar estabilidade e governabilidade.

Porém, Aristide voltou um tanto diferente e sem todo o carisma que tinha anteriormente. Como diria Weber, o carisma havia se "rotinizado". De fato, o Messias havia começado a mostrar suas limitações. O homem já não era invencível; estava mais perto do ser humano normal e dúvidas pairavam sobre sua capacidade para dirigir realmente o Estado. $\mathrm{O}$ verbo incendiador do profeta já não bastava para convencer. O movimento popular havia sofrido um duro golpe: cerca de 3.000 mortos, e muitos dos dirigentes do movimento haviam se exilado ou conseguiram vistos para partir.

O retorno de Aristide foi condicionado também, entre outras coisas, por um programa econômico de corte claramente neoliberal que, em seguida, Aristide irá contradizê-lo em suas práticas, trazendo uma confusão de orientação econômica nada saudável para o país.

Porém, o sinal mais evidente de fragilidade e de transformação do líder nacionalista e anti-imperialista foi o fato de que Aristide voltou envolvido em uma 
roupagem norte-americana: sua própria guarda de segurança era uma companhia norte-americana, à qual Aristide pagava mensalmente uma quantia vergonhosa para um país tão pobre. A essa altura, estava claro que o importante para o presidente era conservar o poder "custe o que custar". Os princípios poderiam facilmente ser deixados de lado.

No entanto, apesar de tudo, Aristide seguia forte. Para o movimento popular, o retorno de Aristide era uma grande vitória e, como que se "perdoava o líder”. Mas, claro que os sinais de fragilidade se amontoavam. Como consequência de muitas incoerências, uma grande massa de intelectuais, de profissionais bem posicionados, a maioria da classe média, ia se afastando dele. Dentre eles, vários sacerdotes ligados à Teologia da Libertação, como Jean Marie Vincent, jornalistas de renome como Jean Dominique e várias personalidades que representavam uma força moral no Haiti. Mas também se afastariam do Messias, grandes organizações de base existentes no campo, como o movimento camponês de Papaye $\mathrm{e}^{4}$ e a organização camponesa "Tèt kole ti peyizan" (Unidade dos camponeses com poucos recursos).

Mais adiante, o movimento popular chamado por Aristide de Lavalas (avalanche) iria sofrer uma fratura importante. Duas tendências atravessavam o movimento. Uma pensava que o movimento deveria deixar sua atomização e espontaneidade para se estruturar e definir sua organicidade a fim de poder avançar em uma posição melhor. Dentro dessa postura, estavam antigos militantes de partidos marxistas, muitos dos quais haviam lutado na clandestinidade no regime de Duvalier e várias personalidades e organizações de base para as quais a desestruturação do movimento constituía seu calcanhar de Aquiles.

À outra tendência importava bem pouco as coisas de organicidade democrática e de articulação do movimento. Supunham que, com Aristide à frente, essa organicidade retiraria a flexibilidade e criatividade do movimento e criticavam fortemente os partidos políticos. Claro que as experiências traumatizantes dos

\footnotetext{
4 Esse movimento é um dos mais antigos no Haiti e existe desde 1973, na cidade de Papaya,
} localizada na parte centro-oriental, do país. Nota da tradutora. 
partidos dos países socialistas constituíam exemplos para não se repetir. À essa tendência se chamava de "nebulosa" e compreendia todo um volume de gente proveniente principalmente das classes de trabalhadores qualificados e de intelectuais não orgânicos. Essas diferenças de tendências poderiam ter dado lugar a um rico e profundo debate. Mas, a verdade é que muitas pessoas pertencentes à segunda tendência, ou seja, à nebulosa, caíam em uma espécie de idolatria ao líder, o que dificultava toda a análise de ordem racional.

Para encurtar a história, eu diria que a primeira tendência deu nascimento à OPL (Organização do Povo em Luta) que tem uma estrutura semelhante à dos partidos políticos clássicos. Por outro lado, forçado a buscar uma configuração ao movimento social, Aristide havia idealizado o que se chamaria "a teoria da roda de bicicleta”, ou seja, uma estrutura na qual eixos múltiplos convergem em direção a um centro único, que seria ele mesmo. Nessa concepção, a pretensa organização é claramente um instrumento a serviço de um chefe, um caudilho. Como consequência disso, ao fazer o partido "Fanmiy Lavalas", os estatutos consagrariam Aristide como o chefe encarregado de pôr vida à organização. Com efeito, o Art. 32 do Estatuto estipula o seguinte: "O posto de Representante Nacional da Organização ficará vazio se o Representante morrer ou renunciar”. Este Representante Nacional (posto mais alto do partido Fanmiy Lavalas) não era ninguém mais que Bertrand Aristide. Está claro que, nessas circunstâncias, a formação do partido respondeu mais à conveniência de ter um instrumento político legal para o acesso ao poder do caudilho do que ao convencimento de participação na disputa eleitoral e obtenção de uma ferramenta que facilitaria a realização das grandes tarefas de democratização e de desenvolvimento do país.

Em seu retorno ao Haiti, em outubro de 1994, restava a Aristide somente pouco mais de um ano para cumprir seu mandato de cinco anos, três dos quais havia vivido no exílio em Caracas e em Washington. Apesar de exilado, era reconhecido por todo o mundo internacional e por grande parte dos haitianos como o presidente legítimo do Haiti. Em outras palavras, davam a Aristide todas as honras e prerrogativas de um grande e verdadeiro chefe de Estado. Sem declarar, Aristide manobrava nos bastidores para "recuperar os três anos passados no exílio" e seus partidários não deixavam de advogar o direito de prolongar o mandato 
presidencial, de maneira que o presidente pudesse cumprir seus cinco anos de mandato dentro do país, situação evidentemente inconstitucional, já que a Carta Magna estipula simplesmente um mandato de cinco anos. Foi por isso que Aristide não apoiou publicamente a candidatura de René Preval, esperando até o final a possibilidade de continuar no poder.

No fim das contas, a Comunidade Internacional, com os Estados Unidos à frente e várias organizações políticas haitianas, entre elas a OPL e os partidos da social-democracia lhe negaram essa possibilidade e Ariside optou então por dirigir o país nos bastidores. Lançou Préval à arena política e continuou dirigindo o país “por trás das cortinas”.

Dessa forma, no final de 1995, um ano depois do retorno de Aristide, sob a imagem de uma coalizão de forças, as eleições presidenciais seriam ganhas por René Préval, homem muito próximo de Aristide e que se considerava como seu irmão gêmeo. No entanto, dentro dessa coalisão, o parlamento foi ganho, em sua maioria pela OPL. Foi nessa circunstância que fui eleito pelo Presidente Préval e pela OPL majoritária no parlamento, para ser primeiro ministro, em março de 1996, depois de mais de um mês de divergências entre a OPL (que, pela lógica, apresentou Gérard Pierre-Charles ${ }^{5}$, seu coordenador geral, como candidato a primeiro ministro) e o presidente Préval.

Como disse anteriormente e como era de conhecimento público, Aristide estava atrás da cadeira de Préval. Aristide e Préval pensaram que eu era provavelmente o mais maleável dentro da OPL, por várias razões: eu não manifestava ambições políticas pessoais, tinha um perfil de técnico ou tecnocrata e, por outro lado, facilitado por meu irmão sacerdote, tinha com Aristide uma boa proximidade.

Aos poucos, os dois homens se dariam conta que, tanto pelo meu espírito de independência como pelo meu apego à OPL e também pelas minhas convicções políticas, eu representava para eles um obstáculo no caminho do poder total

${ }^{5}$ Gerard Pierre Charles foi um dos grandes pensadores de esquerda sobre o Caribe e a América Latina, com ênfase no Haiti. Faleceu em outubro de 2004. Nota da tradutora 
desejado por Aristide. A partir disso tudo, teriam de me tirar. O procedimento? Utilizar o velho método dos caciques: a pressão das ruas.

A partir daí, Aristide lançou seus «chimères» às ruas contra meu governo, supostamente pela política econômica que ele mesmo havia assinado em Paris com as agências internacionais e da qual o presidente Préval se colocava como defensor e porta-voz publicamente. Essa ânsia de poder iria se manifestar nas eleições de abril de 1997 na renovação de um 1/3 do Senado. Aristide esperava ganhar esses postos de qualquer forma para ter maioria no dito corpo legislativo e assim chegar a expandir seu poder. O Conselho Eleitoral, sob a influência do presidente Aristide e certamente com o apoio do presidente Préval, manipulou o sistema de contagem de votos e os resultados, motivo pelo qual tive que denunciar publicamente a fraude. Esses fatos culminaram no processo que levou à minha renúncia no mês de junho e à minha saída total do governo no mês de outubro, após quatro meses e meio tratando de "assuntos cotidianos".

Depois, o presidente Préval dirigiu sozindo, sem primeiro ministro, durante cerca de dois anos, com Aristide por trás das cortinas e o mesmo presidente não querendo buscar um consenso com o Parlamento para a designação de um primeiro-ministro. O conflito com o parlamento durou até janeiro de 1999, data em que o presidente Préval, baseando-se na argúcia de um Acordo assinado pelos parlamentares, dissolveu o parlamento dirigindo por Decreto até depois das eleições fraudulentas de 2000, em que passou a batuta ao seu mentor Jean-Bertrand Aristide, quando foi instalado um parlamento sob o controle total de Aristide. Como se sabe, as eleições de 2000 deram lugar a um aprofundamento da crise com uma mediação extensa e lamentavelmente infrutífera da OEA que continuou até a queda de Aristide em fevereiro de 2004.

Junto com o desejo do presidente Aristide de abarcar o poder total, as organizações populares, ou seja, os grupos do movimento social mais identificado com Aristide, iriam desempenhar um papel de grande importância nesse propósito. Frente à não aceitação das eleições presidenciais pela maioria dos partidos e grande parte da população haitiana, frente às exigências da Comunidade Internacional de que se fizessem correções nas eleições legislativas, Aristide foi fechando 
cada vez mais os espaços, encaminhando-se rapidamente em direção a um poder de tipo totalitário, utilizando grupos populares urbanos como forças de choque do poder.

Foi assim que, em dezembro de 2001, quase em uníssono e em diferentes pontos da capital, grupos populares incendiaram os locais de partidos e as residências da maioria dos chefes de partidos reunidos na Convergência Democrática, criada depois das eleições fraudulentas de 2000. Graças à interferência da OEA, as vítimas conseguiram reparação pelos danos materiais sofridos, mas nenhum dos autores desse crime foi castigado conforme a lei. Uma onda de greves e manifestações viriam a sacudir o país. Como resposta, os partidários de Aristide usaram a violência mais descarada para contê-las e não era considerado estranho, por parte do governo, o fato de cada manifestação terminar com sua cota de feridos e mortos. As promessas de desarmamento dos grupos pró-Aristide e o respeito às liberdades políticas feitas à Comunidade Internacional foram totalmente ignorados. As coisas eram tais que em Gonaives, província localizada no centro do país, nasceu as chamadas «Forças Armadas Canibais» dirigidas por Amiot Metayer, um partidário fervoroso de Aristide, para quem a OEA exigiu em vão a prisão. Depois, quando Metayer passou a ser um fardo pesado demais para se carregar, foi simplesmente liquidado sem que tivesse a oportunidade de ser julgado.

A impunidade total era a norma para qualquer pardidário do poder.Sabe-se do caso da morte do jornalista Brignol Lidor, morto a marretadas; nesse caso, os crimonosos declararam a autoria do crime sem que o aparato de justiça fizesse qualquer coisa para prendê-los. $\mathrm{O}$ dado que iria provocar muita reação foi o fato ocorrido na Faculdade de Ciências Humanas da Universidade de Estado do Haiti, no final de 2003, quando os partidários de Aristide, querendo dar uma lição aos estudantes, entraram na faculdade batendo em quem encontrassem, resultando em vários feridos e duas pernas quebradas do Reitor, que tratou de intervir a favor da Faculdade.

Foi nessas circunstâncias que os partidos políticos da Convergência e vários grupos reunidos na "Sociedade Civil” formaram a "Plataforma Democrática” cujo objetivo declarado era forçar Aristide a renunciar e abandonar o poder. Apesar da 
repressão tanto dos chimères de Aristide como da policía avassalada por Aristide, a oposição continuava se manifestando quase que diariamente, sendo os estudantes os mais determinados a não se deixarem intimidar. Foi nesse já conturbado cenário que os grupos dos ex-militares fizeram sua aparição no Centro e no Norte do país, chegando praticamente a ocupar a metade dele, com cinco dos dez departamentos sob seu controle e ameaçando chegar a Porto Príncipe.

A Comunidade Internacional, naturalmente com os Estados Unidos à frente, que se havia oposto ferreamente à saída de Aristide, a partir desse momento mudou de rumo e forçou, além da partida de Aristide no dia 29 de fevereiro 2004, a instalação de um presidente e de um governo provisórios, que durariam pouco mais de dois anos.

Os partidários de Aristide já haviam começado a iniciar a vingança, transformando Porto Príncipe, poucos dias antes da queda de Aristide, em um inferno onde a oposição não se atrevia nem a sair às ruas. Ocorreram inúmeros saques e vandalismos contra os opositores a Aristide, principalmente aos homens e mulheres de negócio. Depois de sua partida, Porto Príncipe estava como que sitiada pelos partidários de Aristide, que se dedicaram ao vandalismo mais descarado, apesar da presença das tropas enviadas pelas Nações Unidas. Mais adiante, em 29 de setembro de 2004, dia do aniversário do golpe militar de Aristide em 1991, os chimères iniciaram a famosa "Operação Bagdá», liquidando quem encontrassem em seu caminho e tomando de surpresa todos aqueles e aquelas que duvidassem da vontade e da capacidade dos partidários de Aristide de levar a cabo suas ameaças. Porto Príncipe se transformou em um inferno até que as forças de ordem, ou seja, a Polícia Nacional e as Tropas da MINUSTAH decidiram levar seu papel a sério.

A situação de insegurança de hoje (apesar de demonstrar um avanço positivo), quase um ano após a chegada do presidente Préval ao poder, não é mais do que a continuidade da regressão de uma parte do movimento social que levou Aristide ao poder. Por sorte, setores importantes do movimento buscaram outro caminho político ou se dedicaram a trabalhos com organizações comunitárias de base. Muitos e muitas foram para suas casas. Hoje se constata uma retração do conjunto das organizações que alimentaram e deram suporte ao movimento social de 1986. 
Existe a esperança de que os atores sociais que escreveram páginas gloriosas a partir de 1986 possam se reanimar e empreender o caminho de reconstrução do país. Se assim for, muitos dos postulados que levaram aos desvios e às tragédias vividas deverão ser modificados.

Esse espaço, porém, não é o de análise futura. Basta dizer, por agora, que a articulação entre movimento social, movimento popular e organização política parece ser uma condição de suma importância para levar a cabo as árduas tarefas de reconstrução e de desenvolvimento nacional; e que todo paralelismo entre forças sociais e forças políticas encerra o perigo de um autoritarismo descontrolado. 